\title{
Pulmonary transplantation in Mounier-Kuhn syndrome: A case report
}

\author{
Sonia S. Shah, MD, ${ }^{a}$ Demet Karnak, MD, ${ }^{\mathrm{c}}$ David Mason, MD, ${ }^{\mathrm{b}}$ Sudish Murthy, MD, ${ }^{\mathrm{b}}$ Gosta Pettersson, MD, \\ Marie Budev, DO, MPH, and Atul C. Mehta, MD, ${ }^{a}$ Cleveland, Ohio, and Ankara, Turkey
}

M ounier-Kuhn syndrome (MKS) is a rare disorder of unknown cause that is characterized by atrophy of the elastic and smooth muscle of the tracheobronchial tree, tracheobronchomegaly (TBM), and severe bronchiectasis. ${ }^{1}$ There is male predominance, and patients usually present in their adult life. Diagnosis is established on the basis of radiologic findings of TBM, diverticulosis, outpouching of the airway wall on lateral chest radiography, and characteristic endoscopic findings. ${ }^{2}$ Treatment is mainly supportive. Symptomatic patients with airway collapse might require endobronchial stenting. $^{3}$ To our knowledge, lung transplantation has not been reported in patients with MKS. We report the first patient with MKS who underwent successful lung transplantation. Despite significant discrepancy in the airway diameter between donor and recipient bronchi, anastomoses healed without any local complications.

\section{Clinical Summary}

A 59-year-old woman with known diagnosis of bronchiectasis for the past 27 years presented for further evaluation. Her past medical history was significant for rheumatoid arthritis and gastroesophageal reflux disorder. A chest radiograph revealed upper lobe bronchiectasis. Baseline laboratory tests revealed increased erythrocyte sedimentation rate $(61 \mathrm{~mm} / \mathrm{h})$ and C-reactive protein level $(33 \mathrm{mg} / \mathrm{L}$; normal range, 0-20 mg/L). Rheumatoid factor and antinuclear antibody levels were mildly increased. Her forced expiratory volume in 1 second, diffusion capacity, forced vital capacity, total lung capacity, and residual volume were 33\%, 33\%, 52\%, 109\%, and $20 \%$ of predicted value, respectively. Resting oxygen saturation was $95 \%$ with desaturation to $89 \%$ with exercise. Sputum cultures were positive for Pseudomonas aureginosa. Despite appropriate treatment, she continued to deteriorate and required multiple hospitalizations.

From Pulmonary Diseases and Critical Care Medicine ${ }^{\mathrm{a}}$ and Cardiothoracic Surgery, ${ }^{\mathrm{b}}$ Cleveland Clinic Foundation, Cleveland, Ohio, and the Department of Chest Diseases, Ankara University Schools of Medicine, ${ }^{\mathrm{c}}$ Ankara, Turkey.

Dr Karnak is supported by the National Institutes of Health/National Cancer Institute, USA and Tubitak, Turkey.

Received for publication Oct 26, 2005; revisions accepted Nov 23, 2005; accepted for publication Nov 30, 2005 .

Address for reprints: Atul C. Mehta, MD, FCCP, FACP, Pulmonary and Critical Care Medicine, Section of Bronchology, Lung Transplant Team/ A90, 9500 Euclid Avenue, Cleveland, OH 44195 (E-mail: mehtaa1@ ccf.org).

J Thorac Cardiovasc Surg 2006;131:757-8

$0022-5223 / \$ 32.00$

Copyright $\odot 2006$ by The American Association for Thoracic Surgery

doi:10.1016/j.jtcvs.2005.11.029
At 1 year after the initial presentation, pulmonary function tests demonstrated worsening of forced expiratory volume in 1 second and diffusion capacity to $15 \%$ and $48 \%$ of predicted value, respectively. Computed chest tomography demonstrated varicose bronchiectasis, bronchial wall thickening, and TBM predominantly involving the central airways, which is consistent with MKS. Measurements of the airway diameters are depicted in Table 1. Flexible bronchoscopy confirmed the diagnosis of MKS by revealing large diverticula in the tracheal mucosa, TBM with diffuse inspissated secretions, and absence of posterior longitudinal muscle of the endobronchial tree. The patient was enlisted for lung transplantation.

At 2 years after initial presentation, the patient underwent bilateral lung transplantation. An appropriate donor for the patient was found. Bronchial anastomoses were performed with running membranous 4-0 Prolene sutures with interrupted 4-0 cartilaginous approximations. Degree of bronchomegaly was not as severe as tracheomegaly and posed little difficulty during the anastomoses. Postoperative computed chest tomography revealed outpouching on her native trachea and discrepancy in the caliber diameters in donor and recipient bronchi (Figure 1). Our patient had a prolonged postoperative course complicated by multiple failed extubations caused by $P$ aureginos $a$-induced pneumonia and respiratory insufficiency. A tracheostomy was performed on the 15 th postoperative day. Development of Clostridium difficile-induced colitis, steroid myopathy, acute renal failure, myocardial infarction, and atrial fibrillation were other complications. Weeks after the discharge, she required readmission for $P$ aureginosa-induced pneumonia. Her condition gradually improved with antibiotics, and she was eventually weaned off the ventilator and decannulated during the ninth week of transplantation. The patient required 5 weeks of institutionalized rehabilitation. At 2 months after decannulation, while the dose of prednisone was maintained at $5 \mathrm{mg} / \mathrm{d}$, her tracheal stoma failed to heal and required surgical closure.

\section{Discussion}

MKS is a rare disorder of unknown cause characterized by marked dilatation of the airways measured as increase in transverse diameter, tracheal diverticulosis, bronchiectasis, and recurrent pulmonary infections. ${ }^{1,4-6}$ Pathomorphologically, there is mucosal herniation between tracheal rings, leading to tracheal diverticulosis and promoting frequent bacterial colonization. Absence of longitudinal fibers and thinning of the muscular layer of the airway walls are most prominent endoscopic findings. Weakness of the airways leads to inefficient cough and mucus retention. Excessive sputum production results in dyspnea, respiratory insufficiency, and eventually death. ${ }^{7,8}$

Chest radiography and computed tomographic scanning reveal diameters of the trachea, right main bronchus, and left main bronchus that exceed $3.0,2.4$, and $2.3 \mathrm{~cm}$, respectively, which is diagnostic for MKS. ${ }^{1,9-11}$ 
TABLE 1. Patients' airway diameters used for establishing the diagnosis of Mounier-Kuhn syndrome

\begin{tabular}{|c|c|c|c|c|c|}
\hline & $\begin{array}{c}\text { Trachea } \\
\text { (subcarinal junction) }\end{array}$ & $\begin{array}{c}\text { Trachea } \\
\text { (midsternum) }\end{array}$ & Carina & $\begin{array}{c}\text { Right } \\
\text { main bronchus }\end{array}$ & $\begin{array}{c}\text { Left } \\
\text { main bronchus }\end{array}$ \\
\hline Transverse diameter & 2.6 & 2.6 & 2.1 & 1.5 & 1.5 \\
\hline Anteroposterior diameter & 2.5 & 2.6 & 2.9 & - & - \\
\hline
\end{tabular}

Values are given in centimeters.

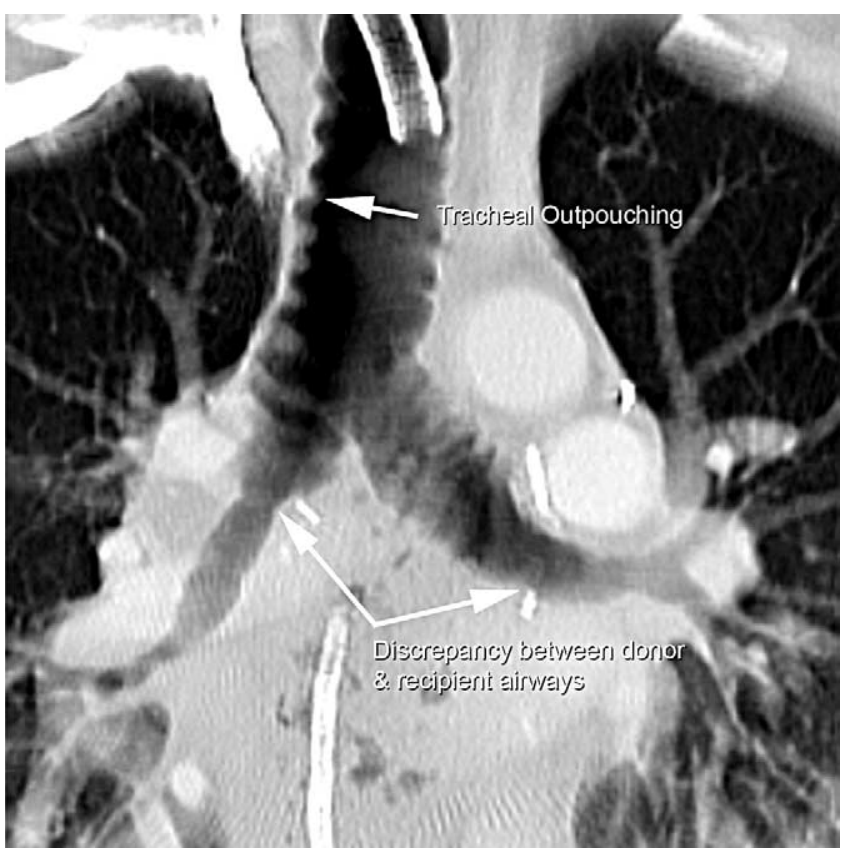

Figure 1. Postoperative chest computed tomographic (coronal view) discrepancy in the caliber diameters in donor and recipient bronchi.

Our patient had primary TBM with diverticulosis extending to main bronchi. Diagnosis was confirmed by means of bronchoscopy, revealing loss of longitudinal muscle fibers along with large diverticula and outpouching in the trachea and main bronchi.

Suggested therapy for MKS is usually symptomatic, including supplemental oxygen, chest physiotherapy along with smoking cessation, and prophylaxis against pneumonia, influenza, or both. ${ }^{3,8}$ Dynamic tracheal stenting has been used with limited success. ${ }^{12}$ In our case lung transplantation was eventually successful despite discrepancy in the diameter of donor and recipient airways.
To our knowledge, this is the first patient with MKS undergoing bilateral lung transplantation. After the transplantation, bronchial anastomotic sites remained open. We did experience difficulties in weaning because of the underlying colonization with $P$ aureginosa. Absence of the longitudinal fibers failed to constrict the tracheal stoma and the patient required surgical closure.

Lung transplantation can be successfully performed in MKS. Patients might require prolonged ventilatory support and hospitalization.

\section{References}

1. Mounier-Kuhn P. Dilatation de la trache'e: constatations, radiographiques et bronchoscopies. Lyon Med. 1932;150:106-9.

2. Schoor JV, Joos G, Pauwels R. Tracheobronchomegaly: the MounierKuhn syndrome; report of two cases and review of the literature. Eur Respir J. 1991;4:1303-6.

3. Goldstein LS, Walsh JJ, Mehta AC. Mounier-Kuhn Syndrome. J Bronchology. 1997;4:148-9.

4. Luiz CLO, Carlos BF, Cristiane GS, Amarino CO. A 39-year old male with tracheomegaly, tracheal diverticulosis, and bronchiectasis. Chest. 2001;120:1018-20.

5. Himalstein MR, Gallagher JC. Tracheobronchomegaly. Otol Rhinol Laryngol. 1973;82:223-7.

6. Bateson EM, Woo-Ming M. Tracheobronchomegaly. Clin Radiol. 1973;24:354-8.

7. Spencer H. Congenital abnormalities of the lung: congenital tracheobronchomegaly. In: Spencer H, editor. Pathology of the lung. 4th ed. Oxford, United Kingdom: Pergamon Press; 1985. p. 129-30.

8. Sane AC, Effmann EL, Brown SD. Tracheobronchiomegaly: the Mounier-Kuhn syndrome in a patient with the Kenny-Caffey syndrome. Chest. 1992;102:618-9.

9. Katz I, Levine M, Hermam P. Tracheobronchomegaly (Mounier-Kuhn Syndrome): CT diagnosis. AJR Am J Roentgenol. 1962;88:1084-94.

10. Vock P, Spiegel T, Fram EK, Effmann EL. CT assessment of the adult intrathoracic cross section of trachea. J Comput Assist Tomogr. 1984; 8:1076-82

11. Blake MA, Chaoui AS, Barish MA. Thoracic case of the day: Mounier-Kuhn syndrome (tracheobronchomegaly). Am J Roentgenol. 1999;173:822, 824-5.

12. Shin MS, Jackson RM, Ho KJ. Tracheobronchomegaly: CT diagnosis. Am J Roentgenol. 1988;150:777-9. 